\title{
Scanning the journals
}

\section{The Gleaner}

Benefits of a systematic approach in the evaluation of fetal facial 3-dimensional volumes

Ramos GA, Kfir M, Lee S, D'Agostini D, Wolfson T, Gamst A, Pretorius DH

J Ultrasound Med 2011; 30 (4): 473-9.

This study was set up to evaluate the accuracy and efficiency of using 3D procedures to teach MFM physicians to display a diagnostic fetal profile and palate from 3D volumes. But for me, the most useful part was the tables outlining in detail the procedures obtaining a fetal profile and obtaining a fetal palate in the 3-orthogonal plane and parallel-view planes. Having a systematic approach is important of course in all aspects of sonography.

\section{Effects of the maternal position and rest on the fetal urine production rate: a prospective study conducted by 3-dimensional sonography using the rotational technique (virtual organ computer-aided analysis) \\ Ulker K, Ceçen K, Temur I, Gül A, Karaca M \\ J Ultrasound Med 2011; 30 (4): 481-6.}

This is an interesting prospective study where 54 pregnant women between 26 and 40 weeks gestation had amniotic fluid indices measured at the time of fetal bladder volume measurements. Both AFI and urine production rates were significantly increased by maternal rest in the left lateral decabitus position. These results are presumably due to an increase in uterine and placental perfusion. It would be interesting to see whether similar effects would be seen on the AFIs in post dates women.

\section{Neonatal abdominal wall defects}

Christison-Lagay ER, Kelleher CM, Langer JC.

Semin Fetal Neonatal Med 2011; Apr 5. [Epub ahead of print]

This Toronto group of surgeons have written a good review. As most of us do not see the follow up of the patients we have diagnosed in utero, it can be useful to be reminded that while most cases have good outcomes, associated anomalies in the case of omphaloceles and bowel dysfunction in gastroschisis can lead to morbidity and even mortality.

\section{Sonographically guided tendon sheath injections are more accurate than blind injections: implications for trigger finger treatment}

Lee DH, Han SB, Park JW, Lee SH, Kim KW, Jeong WK J Ultrasound Med 2011; 30 (2): 197-203.

This article caught my eye as we seldom see studies involving cadavers in the ultrasound literature. No previous attempts have been made to map precisely the locations of material injected into the tendon sheath of the fingers. So using 40 fingers from 5 fresh cadavers, this Korean group set about a comparison of sonographically guided tendon injections compared with blind injections. They used a dye so that they could clearly delineate injection tracks at anatomical dissection, beautifully illustrated in the article. They found that there was a statistically significant difference between the two injection methods with the target area successfully entered in $70 \%$ using ultrasound guidance and only $15 \%$ with blind technique.

As tendon sheath steroid injections are common in management of trigger finger and complications can occur with misplaced injections, the authors suggest it is now time for clinical studies on live patients. Rugby league players, take note.

\section{Assessment of corpus callosum biometric measurements at 18 to $\mathbf{3 2}$ weeks' gestation by 3-dimensional sonography} Rizzo G, Pietrolucci ME, Capponi A, Arduini D

J Ultrasound Med 2011; 30 (1): 47-53

As we know, with 2D ultrasound, unless you get a perfectly aligned mid-sagittal fetal brain view on transabdominal scanning, it can be difficult to measure the corpus callosum. Several studies recommend 3-dimensional sonography for better visualisation of the cavum septic pellucidi and the corpus callosum, but none have documented changes in biometry during gestation.

Rizzo and his group studied 361 women with singleton pregnancies with no fetal abnormality and median age of 24 weeks and acquired transabdominal 3D volumes. In 32 fetuses a mid sagittal 2D view was taken for comparison. Analysis was done off-line resulting in reference charts with 5th, 50th and 95th percentiles for corpus callosum, corpus callosum-cavum septi pellucidi complex area and corpus callosum area. They demonstrate linear growth and their reconstructed 3D images corrected well with 2D images. Despite this, the authors suggest that critical decisions about pathology in these areas should not be made only on 3D reconstruction but should include expert re-evaluation of 2D images as well as fetal magnetic resonance imaging.

It is encouraging to read that 3-Dimensional ultrasound is being critically evaluated by groups such as this well know Italian one and not being recommended as the answer for all diagnostic conundrums.

\section{Important announcement from ASAR}

As of 1st July 2011, entrance to the ASAR Register through grandfathering (category 3) will be removed. Applicants can only register by way of Category 1 or Category 2.

If you need further information, please contact the ASAR Secretariat via email at registry@asar.com.au

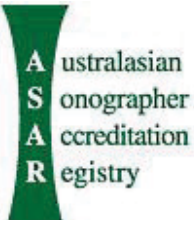

